\title{
RADIKALNA SAMOKRITIKA FILOZOFIJE I MISAONA DOSTIGNUĆA STAROG ISTOKA
}

\begin{abstract}
Sažetak
U knjizi O potrebi filozofije danas: Filozofija između Istoka i Zapada značajni srpski filozof Mihailo Đurić preduzima široko razmatranje teškoća u kojima se nalazi savremena filozofija kao izvorno evropski projekat. Naime, Đurić insistira na evropskom identitetu filozofije. Upravo zbog toga ga zanima recepcija istočnjačke misaone tradicije u modernoj i savremenoj evropskoj filozofiji.
\end{abstract}

Ključne reči: Mihailo Đurić, filozofija, identitet filozofije, Zapad, Istok.

1.

Već na početku svoje knjige $O$ potrebi filozofije danas: Filozofija između Istoka i Zapada, Mihailo Đurić (1925 - 2011) postavlja dijagnozu o odgovornosti filozofije za loše stanje savremenog sveta. U duhu Martina Hajdegera (Martin Heidegger) Đurić kaže da je upravo filozofija „,[...] odlučujuće doprinela čitavom modernom razvoju nauke, tehnike i industrije, te da je niko drugi do ona najpre i najviše odgovorna za katastrofalno stanje u kome se svet danas nalazi“ (Ђурић 1999: 8). Ali i sama filozofija, ne samo neki njen određeni pravac već filozofija kao takva je „,[...] odavno radikalno dovedena u pitanje" (Op. cit.), i to upravo od samih filozofa. Đurić ne pominje da je ona dovedena u pitanje samim razvojem nauke odnosno njenim diferencijacijama i sve užim specijalizacijama. Njega zanima pre svega ono dovođenje u pitanje filozofije koje dolazi iz nje same. Ono danas dolazi, kaže Đurić, iz postidealističkih i postmodernističkih

Fakultet za strane jezike, Palmira Toljatija 3, 11070 Novi Beograd aleksandar.prnjat@gmail.com 
filozofskih krugova (105). Tim krugovima pripada i Filip Laku - Labart (Philippe Lacoue - Labarthe), ali o tezi da je filozofija došla do svog kraja ima različito mišljenje od Hajdegera i Deride (Derrida), od kojih inače crpi produktivne impulse, pa Đurić sa izrazitim odobravanjem navodi njegovu ocenu da smo još uvek na terenu filozofije (105).

1.2.

Đurić smatra da je „radikalna samokritika filozofije” (isto) neka vrsta izokrenute verzije Hegelovog shvatanja o kraju filozofije. Doduše, sa tom ključnom razlikom što je kod Hegela reč bila o promeni lika filozofije kada ona u svom razvoju dostiže najviši stupanj, dok je kod postmodernističkih kritičara filozofije, reč o njenoj propasti (105 - 106).

Upravo ova vrsta diskursa o propasti filozofije, koji se bazira na totalnom sumnjičenju logosnog karaktera mišljenja, čini po Đuriću jedan od glavnih pobuda „današnje potrebe za filozofijom” (101). Naveo sam izraz „potrebe za filozofijom” zato što Đurić i u naslovu knjige kao i na drugim mestima u samoj knjizi koristi izraz „potreba filozofije” koji bi mogao biti shvaćen kao da je reč o potrebi same filozofije, a ne potrebi za njom. ${ }^{1}$

\section{3.}

Đurić ukazuje da su radikalnu samokritiku filozofije posle nemačkog idealizma (razdoblje, koje kao i mnogi istoričari filozofije, naziva savremenom filozofijom) započeli Šopenhauer (Schopenhauer), Marks (Marx), Niče (Nietzsche) i Kjerkegor (Kierkegaard) $(27 ; 107)$. Ali, smatra da je upravo „[...] najnovija pomodna, radikalna samokritika filozofije" (101) ta koja danas najviše izaziva potrebu za filozofijom. Nju, kaže Đurić, ne podstiče toliko ono što je u ovoj kritici negativno, već upravo njen pozitivan program, ono ka čemu ona teži, a to je favorizovanje čulno - emocionalnih, odnosno, opažajno - intuitivnih načina saznanja (106). Takav program protivan je klasičnom određenju filozofije, pa ga utoliko Đurić određuje kao antifilozofski usmeren. ${ }^{2}$

1 Đurić je načisto sa tim da postoji „[...] dvostruki smisao ove sintagme” (Ђурић 1999: 15) koju preuzima iz Hegelovog spisa Razlika između Fihteovog i Šelingovog sistema filozofije. Vidi: Hegel 1983.

2 On izraz „antifilozofski” upotrebljava sa jednim neizgovorenim ali jasno podrazumevanim nipodištavajućim, gotovo prezrivom tonom. Za njega je,u skladu sa tradicijom, antifilozofsko nešto skandalozno. Ali, za Badijua (Badiou) na primer, izraz antifilozofija nije uvreda, jer predstavlja "glavno određenje" autora kao što su Paskal (Pascal), Ruso (Rousseau), Kjerkegor, Niče, Vitgenštajn (Wittgenstein), Lakan (Lacan). (Badiou 2005: 49). 
2.

Đurić se naročito obrušava na pokušaje povezivanja pozitivnog programa ovih postidealističkih i postmodernističkih izazova tradicionalnom obliku filozofije, programa koji nastoje da izađu iz „uskog evropskog okvira” (107). Neobična je okolnost da neko ko upotrebljava izraz „uzak evropski okvir" to čini da bi kritikovao one koji iz tog uskog okvira nastoje da izađu, odnosno, u ovom slučaju, izvuku filozofiju iz tog okvira i uključe je u „šire svetske tokove” (isto). Ali, Đurić veruje da je duboko promašeno „[...] obraćanje drevnoj istočnjačkoj mudrosti, traženje oslonca u velikim misaonim tradicijama stare Kine, Indije i Japana" (isto). On insistira na evropskom identitetu filozofije. Naime, filozofijom naziva samo onaj oblik mišljenja koji je nastao u staroj Grčkoj.

lako Đurić ne dovodi u pitanje podsticaje za nastanak filozofije koji su došli sa Istoka, on istočnjačkim filozofskim tradicijama, ne priznaje ime filozofije. Njihov uticaj na evropsku filozofiju, koja je postojala takoreći od samih grčkih početaka, jednostavno naziva "misaoni podsticaji” (111 - 113). lako priznaje da bez interesovanja starih Grka za azijske misaone sisteme, misao u Grčkoj možda uopšte ne bi „,...] našla svoj osobeni put, sazrela kao poseban oblik duha" (109). Đurić nikako ne želi da azijskim filozofskim tradicijama prizna išta više od mitsko - pesničkog načina govora (109-110). On stoga izričito naglašava da:

„[...] iako je grčka filozofija počela pod okriljem Istoka, pod njegovim neposrednim uticajem, tako reći ruku pod ruku s njim, ona se uzdigla i razvila nasuprot Istoku kao protivteža azijskoj vezanosti i predanosti tradiciji, kao najčistiji izraz evropskog slobodarskog nastrojenja, kao novi oblik duha, koji žudi za slobodom, koji sledi svoju osobenu istraživačku sklonost, koji postavlja bitno drugačije zahteve i merila, kako na području saznanja tako i na području delanja. U pitanju je kritički duh koji ništa ne prima zdravo za gotovo, već svemu traži razloge i dokaze, koji ništa ne prihvata kao svetinju, niti išta želi da sačuva u nepromenjenom obliku..." (115).

Ovaj žestoki evropocentrizam ne daje nikakav dokaz da u azijskim filozofijama ne postoji traženje razloga i dokaza. lako opravdano uzdiže 
evropsku filozofiju zato što ona „žudi za slobodom”, ostaje nejasno da li je suviše slobodno, a bez pravog poznavanja, procenio sve filozofske tradicije Istoka naprosto kao religijske pokrete (116)? Onda bi suprotnost grčke filozofije u odnosu na „[...] nasleđeni obrazac - mitsko - pesničkog kazivanja i propovedanja" (109 - 110; Ђурић 1995207 - 227) lako bilo preneti na suprotsnost između grčke filozofije i istočnjačkih mitsko pesničkih tradicija, uz nepoznavanje stvarnog sadržaja azijskih filozofija.

\section{3.}

U ovakvom odnosu prema azijskim filozofijama Đurić naprosto sledi Hegela. I dok je Hegelov stav da ne postoji nikakva istočnjačka filozofija, da se na Istoku radi samo o religijskim prestavama razumljiv s obzirom na stanje istraživanja azijskih filozofskih tradicija u Hegelovo vreme, dotle je nejasno na čemu Đurić temelji jednostavno preuzimanje Hegelovih sudova o ovoj temi kao konačnih i bespogovornih. Ništa ne menja na stvari Đurićevo ograđivanje od Hegelovog oštrog odbacivanja istočnjačke filozofije, kao na primer kada kaže da njegova naglašena evropocentrička usmerenost ,[...] mestimično doista poprima crte izvesne zagriženosti i isključivosti” (131). Prilikom izlaganja indioloških istraživanja Fridriha Šlegela (Friedrich Schlegel) (135 - 140) Đurić kritički primećuje da je ovaj „[...] naprosto izjednačavao filozofiju i književnost, brisao svaku razliku između njih" (137). Ovim Đurić ponavlja optužbu koju je Habermas izneo protiv Deridinog dekonstruktivističkog čitanja filozofskih i književnih tekstova ${ }^{3}$. Govoreći o Šopenhaueru Đurić kaže da je on otvoreno prkoseći filozofima svoga doba a posebno Hegelu, preuzimao različite indijske koncepcije i uključivao ih u sopstvenu filozofiju (142). Đurić ih ne naziva koncepcijama, a još manje bi ih nazvao konceptima, on govori kako je kod Šopenhaurea došlo do prisvajanja „indijskih religijskih slika i predstava” (142). Đurić doduše ne misli da je Šopenhauerovo okretanje prema Istoku nepromišljeno povezano sa radikalnom kritikom uma. On međutim prebacuje Šopenhaueru jednu performativnu protivrečnost: svođenje uma na instrument održanja života, ukida um kao izvor vrednosti, pri čemu je odbavicanje volje za životom jedini način za izbegaranje životnih patnji. Performativna protivrečnost se sastoji

Habermas 1990: 185 - 210. 
u tome što se Šopenhauer, kaže Đurić, „[...] svim silama trudio da pomoću tog istogu uma obrazloži i utemelji svoje shvatanje" (143).

U Ničeovom osporavateljskom nadovezivanju na Šopenhauera, za Đurića je značajno to da je Niče "radikalizovao Šopenhauerivu kritiku uma, možda ponajviše zahvaljujući tome što je iz osnova izmenio stav prema istočnjačkoj misli, što je težište filozofskog susreta između Istoka i Zapada usmerio na traženje novog a ne na ponavljanje starog" (145). To je ono do čega je Đuriću osobito stalo. On nema ništa protiv istočnjačkih misaonih dostignuća, ali pod uslovom da su ona uvučena u kontekst evropske filozofije i u njoj „temeljno obrađena i prerađena” (145).

Đurić se zatim bavi i Šelingovom (Schelling) Filozofijom mitologije zamerajući Šelingu što izraze „teozofija“, „teologija“ i "mistika“ koristi nazmenično sa izrazom „indijska filozofija”. Zgražava ga govor o indijskoj filozofiji „[...] kao tobože ravnopravnom partneru grčkoj filozofiji” (159).

Đurić se naročito obrušava na pojačano interesovanje poznog Hajdegera za istočnjačke filozofske tradicije. Prebacuje mu što je on, koji se prethodno zalagao za jedno izvornije čitanje grčkih filozofskih tekstova, za „[...] njihovo oslobađanje i čišćenje od sholastičkih i raznih drugih iskrivljavanja i izvitoperavanja" (184), u svojim poznim godinama okrenuo Istoku. Smeta mu što je Hajdeger smatrao da filozofija danas treba da se "udubi u misaoni svet staroga Istoka" (187). Hajdegerova pobuna protiv logike i pojmovnog mišljenja završila je u slepoj ulici mitologije (242). Njegovo dugogodišnje iskušavanje istočnjačkih filozofija za Đurića je ništa drugo do Hajdegerovo „[...] dirljivo dugogodišnje zamajavanje Istokom” (192). I ne samo da je puko „zamajavanje” već je i:

„[...] trajna opomena na rastuću samoubilačku sklonost filozofije u našem vremenu, koja je još zloslutnija i zlokobnija nego Hajdegerovo žalosno kratkotrajno zaluđivanje nacionalsocijalističkim pokretom u Nemačkoj" (192).

Đurić nigde ne objašnjava zašto bi Hajdegerovo „zamajavanje Istokom" bilo zlokobnije od Hajdegerovog oduševljenja nacizmom. To se može objasniti jedino ukoliko se evropski oblik filozofije shvati kao toliko sudbonosan ne samo za evropskih kulturni identitet već i za celo čovečanstvo. Naknadna Đurićeva zalaganja za uzajamno uvažavanje 
između nas Evropljana i sa druge strane Kineza, Indusa i Japanaca ne ublažava ovakve ocene. Ako se već zalaže za dijalog na ravnopravnoj osnovi (193), zašto unapred isključuje mogućnost da u tom dijalogu strane neće izmeniti ponešto od svojih prvobitnih pozicija. Spremnost na učenje od istočnjačkih filozofija ne implicira da bi evropski oblik filozofije odjednom odustao od slobodnog preispitivanja svih pretpostavki, odnosno da bi odustao od načela slobode.

\title{
Literatura:
}

Badiou, Alain. Metapolitics. London, New York: Verso, 2005.

Ђурић, Михаило. О потреби филозофије данас: Филозофија између Истока и Запада. Нови Сад: Прометеј, 1999.

Ђурић, Михаило. Хуманизам као политички идеал: Оглед о грчкој култури. Београд: Терсит, 1995.

Habermas, Jürgen. The Philosophical Discourse of Modernity: Twelve Lectures.

Cambridge, Massachusetts: The MIT Press, 1990.

Hegel, Georg Vilhelm Fridrih. Razlika između Fihteovog i Šelingovog sistema filozofije. U Hegel, Georg Vilhelm Fridrih. Jenski spisi. Sarajevo: Veselin Masleša, 1983.

\section{Aleksandar Prnjat}

\author{
RADICAL SELF-CRITICISM \\ OF THE PHILOSOPHY AND THE ASIAN THOUGHT
}

\section{Summary}

In the book On the Needs of Philosophy Today: Philosophy between the East and the West, a prominent Serbian philosopher, Mihailo Djurić considers extensively the difficulties of contemporary philosophy as the original European project. Namely, Djurić insists on the European identity of philosophy. For this reason, he is interested in the reception of the Eastern thought tradition in modern and contemporary European philosophy.

Key words: Mihailo Djurić, philosophy, identity of philosophy, West, East. 